\title{
Malignant lymphoma of the conjunctiva following Hodgkin's disease
}

\author{
HANS E GROSSNIKLAUS, '? DIANE C FARHI,' BRUCE R JACOBSON,' \\ AND MARY FAITH ABBUHL'
}

From the 'Division of Ophthalmology and 'Institute of Pathology, University Hospitals of Cleveland and Case Western Reserve University, Cleveland, Ohio, USA

SUMmARY A 64-year-old woman with mixed cellularity Hodgkin's disease diagnosed in 1972 developed a malignant lymphoma of the conjunctiva 14 years later. She had undergone combined chemotherapy and radiation therapy for Hodgkin's disease. Non-Hodgkin's lymphomas developing after Hodgkin's disease have been reported with increasing frequency in recent years. It is important to recognise a separate malignant lymphoma in a patient with Hodgkin's disease because of the different treatment offered for each of these diseases.

Hodgkin's disease rarely involves the conjunctiva. ' However, non-Hodgkin's lymphoma of the conjunctiva is not uncommon. ${ }^{3+}$ There have been several reports in recent years describing patients with Hodgkin's disease who later developed a separate non-Hodgkin's lymphoma. ${ }^{5-15}$ There has been some suggestion that the separate lymphoma may be related to chemotherapy or radiation therapy for the Hodgkin's disease. ${ }^{11+1+}$ It is also possible that newer diagnostic techniques permit the diagnosis of nonHodgkin's lymphoma in lesions previously interpreted as Hodgkin's disease.

We report the clinical and histopathological findings in a 64-year-old woman with treated Hodgkin's disease who presented with a conjunctival malignant lymphoma. Immunohistochemical analysis and cell flow cytometry were used to characterise the conjunctival lymphoma.

\section{Case report}

A 64-year-old white woman was examined for irritation of her right eye which had been present for approximately one week. Examination showed her best corrected visual acuity to be 20/20 in each eye. Pupillary and ocular motility testing were normal. External examination was remarkable for an $8 \times 8$ $\mathrm{mm}$ salmon-coloured subconjunctival mass in the area of the plica semilunaris with extension into the Correspondence to Hans Grossniklaus MD, Division of Ophthalmology, 2078 Abington Road, Cleveland, OH 44106, USA. inferior fornix of her right eye (Fig. 1). The rest of the external, tonographic, and funduscopic examinations were normal. A physical examination and chest $x$-ray showed no lymphadenopathy. An excisional biopsy of the subconjunctival mass was performed (description below).

The patient's past medical history was significant for Hodgkin's disease diagnosed 14 years previously. The Hodgkin's disease was diagnosed by hilar and right scalene lymph node biopsies performed in 1972 after a chest $x$-ray showed a mediastinal mass (Fig. 2) and physical examination showed an enlarged right scalene lymph node. Staging procedures including bone marrow biopsies, splenectomy, and liver biopsy

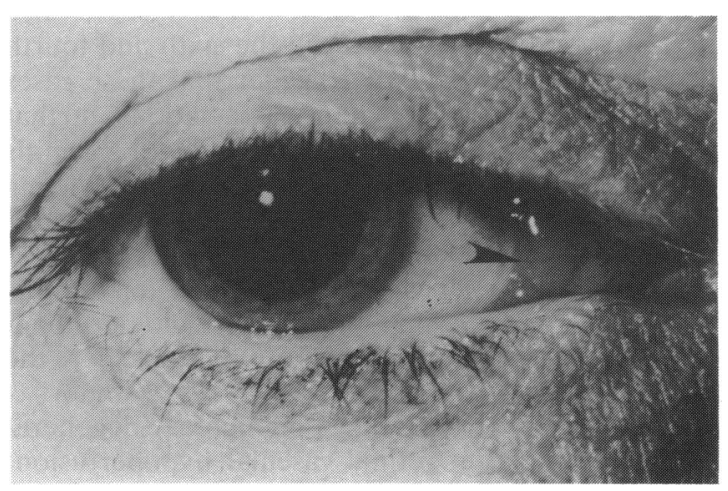

Fig. 1 Appearance of right eye with medial, salmoncoloured conjunctival mass (arrowhead). 


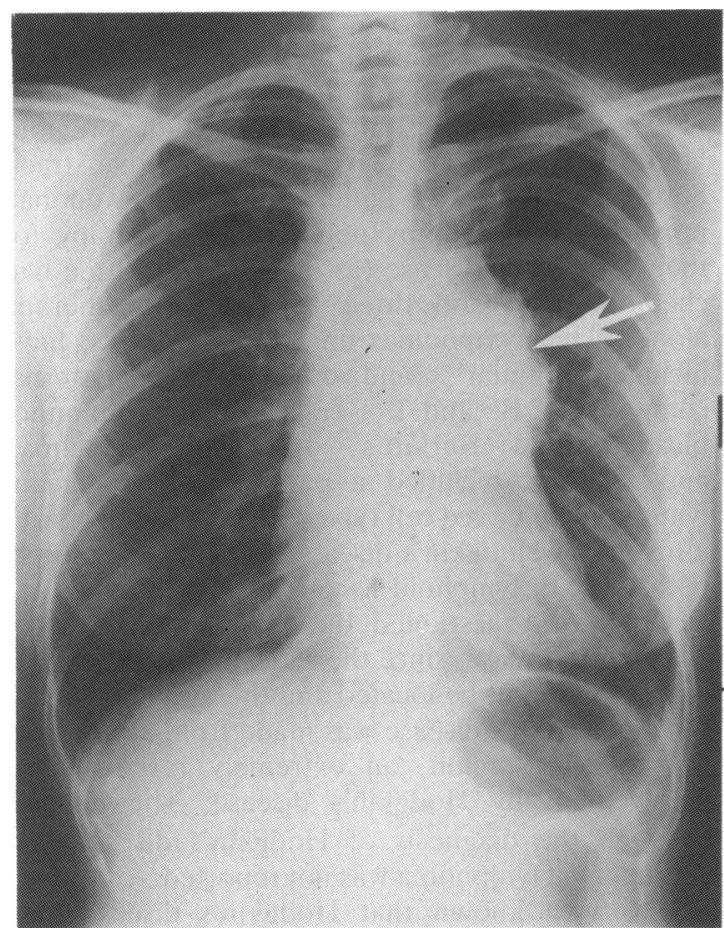

Fig. 2 Radiographic appearance of mediastinal enlargement (arrow) noted in 1972.

failed to show tumour. She was considered to have Hodgkin's disease, stage IIB. Radiation therapy totalling 4400 rads was administered to her upper mantle. She did well until 1973, when she developed a left pleural effusion. A thoracentesis of the left pleural space showed lymphocytes, neutrophils, and mesothelial cells. She was given six courses of chemotherapy including carmustine vinblastine, and cyclophosphamide, the last treatment being administered on 10 April 1974.

Four subsequent treatments of MOPP (nitrogen mustard, Oncovin (vincristine, prednisone, and procarbazine) were given, the last on 12 July 1974 . The patient developed disseminated herpes zoster on 27 July 1974, which resolved after systemic treatment with cytarabine. She received no further radiation or chemotherapy for her Hodgkin's disease. Bone marrow biopsies and a liver biopsy were negative for tumour in 1975, and her course was unremarkable until the development of her conjunctival lesion in 1986.

\section{PATHOLOGICAL FINDINGS}

Examination of the cervical and hilar lymph nodes excised in 1972 showed fragments of lymph node surrounded by loose connective tissue. Nearly the entire nodal architecture was effaced by an infiltrate

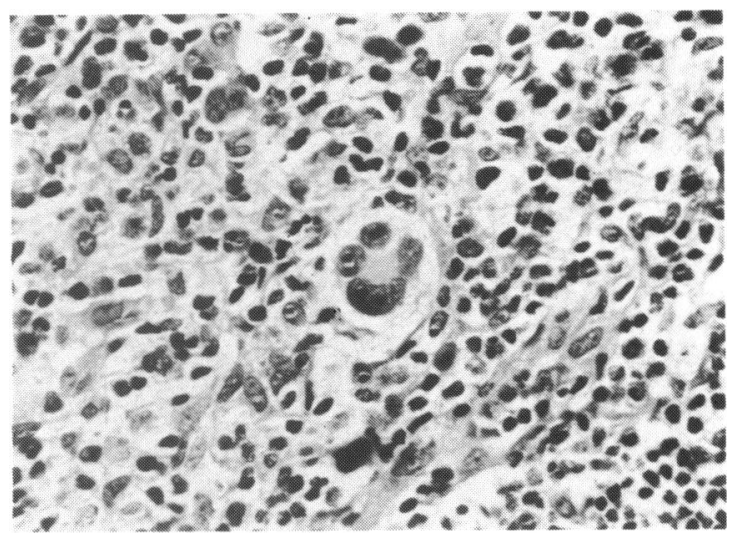

Fig. 3 Reed-Sternberg cell variant surrounded by eosinophils, lymphocytes, and histiocytes. Haematoxylin and eosin.

of histiocytes, lymphocytes, eosinophils, and plasma cells in which were scattered numerous diagnostic Reed-Sternberg cells and abundant mononuclear and multilobulated Reed-Sternberg variants (Fig. 3). Rare lacunar cells were present, but there was no evidence of lamellar fibrosis. The Reed-Sternberg cells and variants were strongly positive for Leu-Ml. The findings were diagnostic of Hodgkin's disease, mixed cell type.

The conjunctival specimen consisted of mucosa and underlying soft tissue, infiltrated by a dense population of small cleaved and large cleaved and non-cleaved lymphocytes (Figs. 4A, B). Admixed were numerous small, round lymphocytes with compact chromatin. There was no evidence of follicle formation; plasmacytoid features were not seen. No Reed-Sternberg cells were present. A portion of the fresh tissue was submitted for cell surface marker studies by flow cytometry, yielding the following results: anti-surface immunoglobulin (SIg) $72 \%$, anti-kappa $39 \%$, anti-lambda $35 \%$, anti-OKIa-l $77 \%$, anti-OKT1 $28 \%$, anti-OKT3 $22 \%$, anti-cALLa $25 \%$, and anti-TAC $6 \%$. The finding of $28 \%$ mature $\mathrm{T}$ cells (OKT1 and OKT3 positive) indicated a significant admixture of reactive lymphocytes. The results were most compatible with a population of lambda-bearing neoplastic cells (approximately $25 \%$ ) admixed with reactive $B$ and $T$ cells. The presence of benign, reactive lymphocytes was often seen in malignant lymphoma, as in other neoplasms, and in this case represented a significant proportion of the cells separated from the tissue prior to flow cytometry. The recovery of relatively low numbers of neoplastic SIg-bearing cells has been previously noted. ${ }^{16}$ This interpretation was further supported by immunocytochemical studies done on frozen sections, showing numerous small, round lympho- 


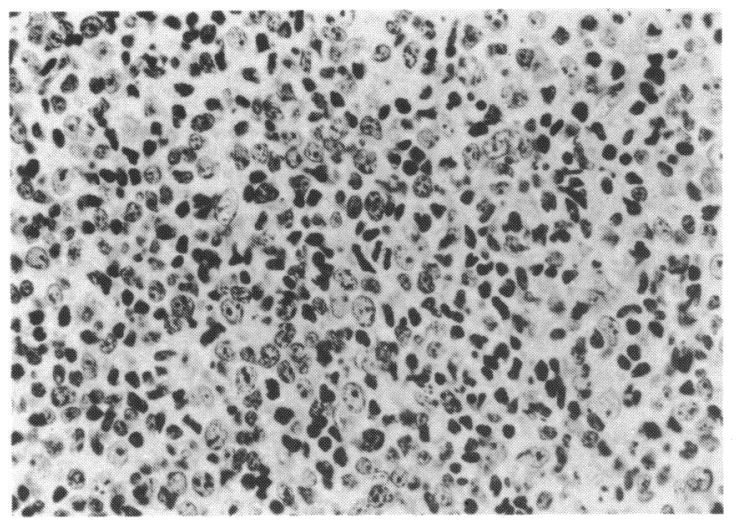

Fig. 4A Conjunctiva with mixed population of small and large lymphoid cells with prominent nuclear irregularities. Haematoxylin and eosin.

cytes staining as $\mathrm{T}$ cells (Leu 1, Leu 5 positive), the majority having a helper $\mathrm{T}$ cell phenotype (Leu 3 ) and a minority suppressor T cell phenotype (OKT 8). These constituted about $25 \%$ of the cells seen, in accordance with the flow cytometry results. Immunocytochemical studies on frozen and B5-fixed paraffinembedded tissue showed staining of abnormal, large lymphoid cells for lambda and IgG in approximately $5 \%$ of cells; in rare large lymphoid cells staining for IgM was noted.

\section{Discussion}

It is not unusual for a second malignant neoplasm to develop in patients with Hodgkin's disease. ${ }^{.7-20}$ The most common second malignancy is acute myeloblastic leukaemia. ${ }^{21}$ Non-Hodgkin's lymphomas have been reported to occur as a second malignancy with

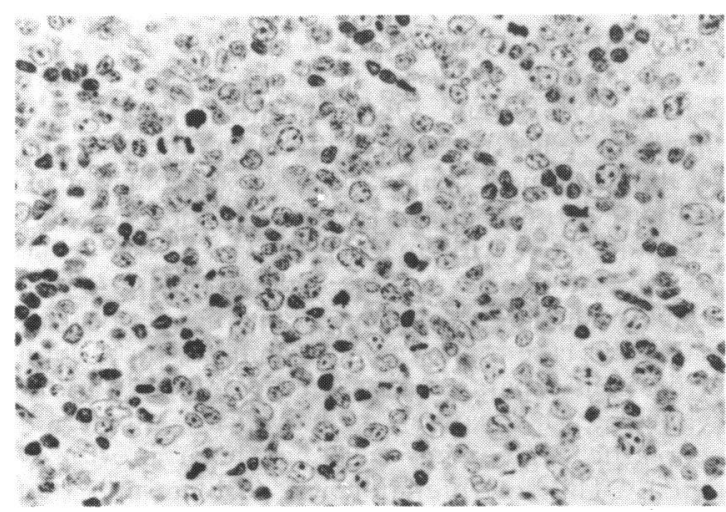

Fig. 4B Conjunctival lymphoma where larger lymphoid cells are more numerous. Haematoxylin and eosin. an estimated frequency of $0.9 \%$ to $2.1 \% .^{512}$ Jacquillat et al. ${ }^{1+}$ reviewed the literature and found that approximately $50 \%$ of the reported cases of nonHodgkin's lymphoma in patients with previous Hodgkin's disease involved the digestive tract. Seventeen of the 24 patients they reviewed had previous chemotherapy plus radiation therapy for their Hodgkin's disease (as in our case), three had chemotherapy, and three had radiation therapy alone. The lymphomas in previous cases have included nodular ${ }^{811}$ and diffuse $e^{57-111314}$ patterns, composed of $B^{12}$ and $T^{1112}$ cells, including immunoblastic $^{\text {14 }}$ and Burkitt's ${ }^{22}$ lymphoma. Sigelman and Jakobiec included a patient with malignant lymphoma of mixed cell type of the conjunctiva with a history of Hodgkin's disease in their review of 40 patients with lymphoid lesions of the conjunctiva. ${ }^{3}$ The authors questioned the original diagnosis of Hodgkin's disease, since the slides from the original biopsy could not be located and the original diagnosis of Hodgkin's disease was made from a biopsy of the tonsillar region, an extremely rare site for involvement by Hodgkin's disease. The interval between the diagnosis of Hodgkin's disease and conjunctival lymphoma was not reported.

It is well known that Hodgkin's disease may progress to a histopathological subtype with a less favourable prognosis; transformation to nonHodgkin's lymphoma is believed not to occur. ${ }^{15}$ It is possible for both non-Hodgkin's lymphoma and Hodgkin's disease to occur concurrently in a rare condition termed 'composite lymphoma'..$^{23}$ In our case 14 years elapsed between the original diagnosis and the appearance of the conjunctival lymphoma, precluding the possibility of composite lymphoma.

The phenomenon of a second lymphoma occurring in patients with Hodgkin's disease appears to have been recognised only recently. ${ }^{12+}$ Two explanations for these recent observations are proposed. It is possible that with newer diagnostic techniques, including immunohistochemical analysis for $\mathrm{T}$ and $\mathrm{B}$ cells, ${ }^{+}$malignant lymphomas are recognised which may previously have been mistaken for Hodgkin's disease. Alternatively, chemotherapy and radiation therapy may predispose patients with Hodgkin's disease to a second lymphoproliferative disorder. ${ }^{101+1+}$ Patients with Hodgkin's disease may have defects in their immune surveillance system which predisposes them to second malignancies. A combination of these explanations may be a factor in the relatively recent descriptions.

It is important for the ophthalmologist and the pathologist to recognise the possibility of nonHodgkin's lymphoma occurring in the conjunctiva of patients with previous Hodgkin's disease, as these malignancies require different treatment. 


\section{References}

1 Faulborn J. Malignant granulomatosis of the conjunctiva. Klin Monatsbl Augenheilkd 1970; 156: 409-16.

2 Torcynski E. Hodgkin's disease with conjunctival involvement. Teaching Slide Exchange Program, 1978.

3 Sigelman J, Jakobiec FA. Lymphoid lesions of the conjunctiva: relation of histopathology to clinical outcome. Ophthalmology 1978; 85: 818-43.

4 Ellis JH, Banks PM, Campbell RJ, Liesgang TJ. Lymphoid tumors of the ocular adnexa. Clinical correlation with the working formulation and immunoperoxidase staining of paraffin sections. Ophthalmology 1985; 92: 1311-24.

5 Krikorian JG, Burke JS, Rosenberg SA, Kaplan HS. Occurrence of a non-Hodgkin's lymphoma after therapy for Hodgkin's disease. $N$ Engl J Med 1979; 300: 452-8.

6 Lichtenstein A, Levine AM, Lukes RJ, et al. Immunoblastic sarcoma: a clinical description. Cancer 1979; 43: 343-52.

7 Spaulding MB, Mogavero H, Montes M. Non-Hodgkin's lymphoma after chemotherapy for Hodgkin's disease. $N$ Engl $J$ Med 1979; 301: 384-5.

8 D'Agostino RS. Non-Hodgkin's lymphoma after radiotherapy for Hodgkin's disease. $N$ Engl J Med 1979; 301: 1289.

9 Case records of the Massachusetts General Hospital. $N$ Engl J Med 1980; 302: 389-95.

$10 \mathrm{Kim}$ HD, Bedetti CD, Boggs DR. The development of nonHodgkin's lymphoma following therapy for Hodgkin's disease. Cancer 1980; 46: 2596-602.

11 Lowenthal RM, Harlow RW, Mead AE, Tuck D, Challis DR. Tcell non-Hodgkin's lymphoma after radiotherapy and chemotherapy for Hodgkin's disease. Cancer 1981; 48: 1516-89.

12 Armitage JO, Dick FR, Goeken JA, Foucar K, Gingrich RD. Second lymphoid malignant neoplasms occurring in patients treated for Hodgkin's disease. Arch Intern Med 1983; 143: 445-50.

13 Mims CH, Costanzi JJ. Conversion of Hodgkin's disease to lymphoblastic lymphosarcoma. Oncology 1984; 29: 238-43.

14 Jacquillat C, Khayat D, Desprex-Cureley JP, et al. NonHodgkin's lymphoma occurring after Hodgkin's disease. Four new cases and a review of the literature. Cancer 1984; 53: 459-62.

15 Gowitt GT, Chan WC, Brynes RK, Heffner LT. T-cell lymphoma following Hodgkin's disease. Cancer 1985; 56: 1191-6.

16 Levy N, Nelson J, Meyer P, Lukes RJ, Parker WJ. Reactive lymphoid hyperplasia with single class (monoclonal) surface immunoglobulin. Am J Clin Pathol 1983; 80: 300-8.

17 Arseneau JC, Canellos GP, Johnson R, DeVita VT. Risk of new cancers in patients with Hodgkin's disease. Cancer 1977; 40: 1912-6.

18 Bacarani M, Bosi M, Papa G. Second malignancy in patients treated for Hodgkin's disease. Cancer 1980; 46: 1735-40.

19 Brody RS, Schottenfeld D. Multiple primary cancers in Hodgkin's disease. Semin Oncol 1980; 7: 187-201.

20 Valagussa P, Santoro A, Kenda R, et al. Second malignancies in Hodgkin's disease: a complication in certain forms of treatment. Br Med J 1980; 280: 216-9.

21 Rosner F, Grunwals H. Hodgkin's disease and acute leukemia: report of eight cases and review of the literature. Am J Med 1975; 58: $339-53$.

22 Andrieu JM, Casassus P, Bayle-Weisgerber C, et al. Lymphome de type Burkitt survenant après une maladie de Hodgkin. Nouv Presse Med 1980; 9: 1175 .

$23 \mathrm{Kim}$ H, Hendrickson MR, Dorfman RF. Composite lymphoma. Cancer 1977; 40: 959-76.

Accepted for publication 20 January 1987. 